\title{
Novo mapa do emprego industrial no Brasil: mesorregiões geográficas relevantes
}

\author{
New Map of Industrial jobs In Brazil: relevant geographical mesoregions \\ Nuevo Mapa del Empleo Industrial en Brasil: mesorregiones geográficas \\ relevantes
}

\author{
Claudio Roberto Bragueto ${ }^{1}$ \\ Ana Carolina dos Santos Marques ${ }^{2}$
}

Recebido em 04/2017 - aceito em 07/2017.

\begin{abstract}
RESUMO: Muito embora na organização econômico-social atual haja um destaque considerável para a esfera da gestão, da circulação e do consumo, a indústria continua sendo importante na geração da riqueza social. Em geral há, por parte dos gestores públicos, uma preocupação no sentido de atrair investimentos para os territórios. Portanto, além de impactos socioeconômicos, a industrialização trás consequências importantes na produção do espaço. Nesse contexto, a partir de meados dos anos de 1990, muitos autores passaram a defender a tese de que há uma retomada da desconcentração industrial no Brasil. O objetivo do presente trabalho foi verificar o processo de desconcentração do pessoal ocupado na indústria, tendo como recorte temporal o período de 1995 a 2015. O recorte espacial utilizado foi as mesorregiões geográficas estabelecidas pelo IBGE. Como procedimento operacional utilizouse informações do banco de dados do Ministério do Trabalho e Emprego-RAIS (Relação Anual de Informações Sociais) e mapeamento das mesorregiões geográficas conforme o pessoal ocupado na indústria. A principal conclusão foi que houve no período uma desconcentração do pessoal ocupado na indústria, porém trata-se de uma desconcentração concentrada, pois as mesorregiões de maior crescimento estão, em sua grande maioria, localizadas no Centro-Sul do país.
\end{abstract}

Palavras-chave: Geografia Industrial; Industrialização; Desconcentração industrial no Brasil.

ABSTRACT: Although, in the current social-economical organization, there has been considerable emphasis on management, circulation and consumption of goods, industry continues being important for the generation of social wealth. In general, managers from the public sector are interested in attracting investments for their territories. Therefore, besides the socioeconomic impacts, industrialization brings important consequences to space production. In this context, in the mid -90s, many authors started to support the thesis that there has been a return to an industrial decentralization in Brazil. The objective of this work was to verify the industrial employees' decentralization process, using as timeframe the period between 1995 and 2015. The space area used was the geographical mesoregions established by the IBGE. As operational procedure, this work used information from the Ministry of Labor and Employment - RAIS (Annual Report on Social Information) databanks and the mapping of the geographical mesoregions, according to the number of people employed by the industry sector. The main conclusion was that there was, in this period, a concentrated decentralization of industry workers, since most of the mesoregions with greater growth are located in the Center South of Brazil.

Key words: Industrial geography; Industrialization; Industrial decentralization in Brazil

RESUMEN: Aun cuando en la organización económico social actual haya un destaque considerable para la esfera de la gestión, de la circulación y del consumen, la industria continúa

Geografia (Londrina) v. 26. n. 1. p. $92-103$, jan/jun, 2017.

ISSN 2447-1747 
siendo importante en la generación de la riqueza social. En general hay, por parte de los administradores públicos, una preocupación en el sentido de atraer inversiones para los territorios. Por lo tanto, además de impactos socio económicos, la industrialización trae consecuencias importantes en la producción del espacio. En ese contexto, a partir de la mitad de los años de 1990, muchos autores pasaron a defender la tesis de que hay una retomada de la desconcentración industrial en Brasil. El objetivo del presente trabajo fue verificar el proceso de desconcentración de las personas ocupadas en la industria, teniendo como recorte temporal el período de 1995 a 2015. El recorte espacial utilizado fueron las mesorregiones geográficas establecidas por IBGE. Como procedimiento operacional se utilizaron informaciones del banco de datos del Ministerio del Trabajo y Empleo-RAIS (Relación Anual de Informaciones Sociales) y el mapeo de las mesorregiones geográficas conforme las personas ocupadas en la industria. La principal conclusión fue que hubo en el período una desconcentración de las personas ocupadas en la industria, pero se trata de una desconcentración concentrada, pues las mesorregiones de mayor crecimiento están, en su gran mayoría, ubicadas en el Centro Sur del país.

Palabras clave: Geografía Industrial; Industrialización; Desconcentración industrial en Brasil.

\section{INTRODUÇÃO}

$\mathrm{Na}$ análise sobre a industrialização brasileira, no que se refere à concentração ou desconcentração espacial nos anos posteriores a 1970, de uma maneira geral, a bibliografia identifica claramente dois períodos fundamentais até meados dos anos 1990. O primeiro, entre 1970 e 1985, pode ser caracterizado como o de auge do processo de desconcentração e o segundo, de 1985 até por volta de 1994, em que houve uma inflexão do processo. Para os anos posteriores a 1994, porém, alguns autores acreditam que se configuraria um terceiro período, em que houve uma retomada da desconcentração industrial.

Outro aspecto sobre o tema em questão diz respeito à escala de análise. Uma delas inclui o processo de concentração/desconcentração referente ao estado de São Paulo em relação ao restante do país e outra que enfatiza o processo referente à Região Metropolitana de São Paulo, em relação ao interior do Estado de São Paulo, ou que, além desta, incluem outros estados do país.

As perguntas de investigação que motivam a presente pesquisa são oriundas deste último período, portanto de nosso recorte temporal, que vai de 1995 a 2015. Mais especificamente para o presente trabalho procurou-se abordar a seguinte questão: neste período houve efetivamente uma desconcentração do emprego industrial no Brasil?

Portanto, a dinâmica territorial da indústria brasileira nos anos recentes é o tema da presente pesquisa. Acredita-se que este tema é de interesse por dois motivos principais. O primeiro é pela importância da indústria na produção do espaço e na geração da riqueza social, conforme pode ser constatado no cotidiano, quando se verifica uma "guerra entre os lugares" para a atração de investimentos industriais. Nesta perspectiva concordamos com Botelho (2008, p.19), quando afirma que apesar 
de que a ampliação da esfera da gestão, da circulação e do consumo, possa dar a impressão de uma subordinação crescente da lógica produtiva à lógica do consumo na organização do espaço, a indústria continua importante para a conformação do espaço, pois é na indústria que se produz grande parte da riqueza social.

O segundo motivo diz respeito ao recorte espacial estabelecido. Recentemente, no âmbito da Geografia, poucos trabalhos têm procurado dar uma visão na escala do Brasil e quando ocorre, em geral, utiliza-se como sub-divisões as unidades da federação ou as grandes regiões, conforme a divisão regional do IBGE. $\mathrm{Na}$ presente pesquisa utilizaram-se as Mesorregiões Geográficas estabelecidas pelo IBGE. Sabe-se que para os estudos referentes à indústria este também não é o melhor recorte espacial, pois a indústria se caracteriza pela concentração. Porém, o presente artigo apresenta a primeira abordagem do problema, que posteriormente terá continuidade com destaque para os municípios que se destacam em cada uma das mesorregiões que apresentem número de pessoal ocupado relevante na indústria.

Estabelecidos os recortes temáticos, espacial e temporal, o objetivo do presente trabalho foi verificar o processo de desconcentração do pessoal ocupado na indústria brasileira no período de 1995 a 2015. Desta forma foi utilizado como parâmetro inicial para a determinação das regiões industriais relevantes as mesorregiões geográficas que nos anos de 1995 e 2015 possuíam dez mil ou mais pessoas ocupadas na indústria. A fonte dos dados foi o Ministério do Trabalho e Emprego - RAIS (Relação Anual de Informações Sociais), que apresenta os vínculos empregatícios formais dos setores econômicos. Posteriormente elaborou-se cartas temáticas representando a dinâmica do emprego industrial para o recorte temporal em análise.

\section{DESCONCENTRAÇÃO INDUSTRIAL NO BRASIL A PARTIR DA DÉCADA DE 1990}

A bibliografia sobre a desconcentração industrial no Brasil em geral, destaca dois períodos: o primeiro que pode ser denominado de auge do processo de desconcentração, que vai de 1970 a 1985. O segundo, em que houve uma inflexão do processo com a crise econômica, que vai de 1985 até meados dos anos de 1990 (CANO, 1997; DINIZ, 1995, TINOCO, 2001; AZZONI,1985; DINIZ e CROCCO, 1996, BRAGUETO, 2007).

Se parece haver consenso entre os autores sobre os dois períodos mencionados, a partir de meados dos anos de 1990 o debate volta à tona, pois, estaria havendo uma retomada do processo de desconcentração.

Firkowski (2001), argumenta que há sinais de modificação no: 
[...] processo de desconcentração tal qual ele se apresentava até o início da década de 90 , quando o grande destaque do processo era o interior de São Paulo, na medida em que o deslocamento de unidades industriais se dava predominantemente para o espaço compreendido num raio de cerca de $150 \mathrm{Km}$ a partir da cidade de São Paulo (FIRKOWSKI, 2001, p. 81).

Para a autora, sobretudo a partir da década de 90, a base territorial passível de receber os novos investimentos industriais se amplia consideravelmente, extrapolando os limites fixados pelo processo no período anterior, qual seja, São Paulo, metrópole e interior. (FIRKOWSKI, 2001, p.88).

Porém, nos anos mais recentes, outros aspectos precisam ser levados em consideração na análise da desconcentração industrial, sob pena de se cometer graves equívocos.Partindo das análises de Cano (1997) sobre o caráter integrador do processo de desconcentração relativa da indústria nacional, Tinoco (2001) avança teoricamente quando fala da coexistência de diferentes padrões simultâneos de desenvolvimento industrial, ou seja, o padrão antigo, fordista, e o padrão novo, pósfordista.

Em conclusão, o autor afirma que boa parte das interpretações acerca do desenvolvimento regional brasileiro das últimas três décadas e, em especial sobre as interpretações do processo após 1985, que ele periodiza como sendo o terceiro período ${ }^{3}$, sofre de certo "fetichismo da desconcentração":

[...] ou seja, coisificam (através da continuidade da utilização de conceitos e instrumentos de análise defasados) o processo de desconcentração inicial e não conseguem lidar com o fato de que os fatores estruturais da economia brasileira mudaram significativamente para o terceiro período. [...] O que salientamos aqui é que o processo do terceiro período não pode ser estudado e apreendido pela mesma ótica do segundo, se a base econômica onde ele se efetua está modificando-se de um para outro período. (TINOCO, 2001, p.56).

Partindo dessas premissas, o autor avança na discussão, propondo novos instrumentos de análise da dinâmica industrial brasileira, capazes de medir o real significado econômico do ser metropolitano no Brasil e, consequentemente, da dinâmica regional brasileira, ou em suas palavras:

[...] não nos parece suficiente pensarmos em concentração ou desconcentração dos índices de emprego e produção. $O$ que queremos é saber como os empregos na RMSP se interrelacionam com o restante das atividades econômicas e com as restantes regiões do país. Para o entendimento do espaço econômico da RMSP, é fundamental estudarmos o processo [...] de geração, difusão e apropriação da inovação e dos ganhos advindos de seus usos. (TINOCO, 2001, p.57). 
Portanto, na análise da dinâmica industrial brasileira recente, a intensidade tecnológica dos ramos industriais é um elemento decisivo na interpretação do processo. Como enfatiza Tinoco (2001):

aceitar a existência de transformações estruturais é aceitar a coexistência de diferentes padrões simultâneos de desenvolvimento industrial (essas transformações não atingem todos os setores igualmente). Coexistem o padrão antigo, proveniente ainda da II Revolução Industrial, fordista, com forte ênfase em recursos naturais e/ou intensivos em trabalho, e o padrão novo, pós-fordista, da III Revolução Industrial, intensivo em capital e em conhecimento, os setores de alta tecnologia.

Em suma, devemos reforçar a análise de que as duas etapas são fundamentalmente diferentes. Diferentes não apenas em suas intensidades ou direções, sendo a primeira etapa de inequívoca desconcentração e, a segunda, de problemática conclusão. Diferentes principalmente, ainda, por possuírem substratos econômicos diferentes, além de conjunturas, arranjos institucionais e padrões de desenvolvimento distintos. Um período é caracterizado por requisitos locacionais clássicos (ligados ao padrão fordista de desenvolvimento) e o outro, pela coexistência desses padrões com padrões de localização modernos (requisitos de indústrias de alta tecnologia) (TINOCO, 2001, p.52).

Além das discussões apresentadas por Tinoco, outro aspecto a ser levado em consideração diz respeito ao processo de concentração e centralização na reprodução do capital. Neste sentido, Lencioni(1991)esclarece que:

[...] na perspectiva do estudo da dinâmica da reprodução do capital e na compreensão de que a reprodução do capital tem sua dinâmica relacionada ao desenvolvimento desigual do espaço, é que se pensa estar a chave para compreensão da nova estrutura espacial. Neste sentido, é que os processos sociais e espaciais configuram uma unidade. Nossa posição é a de que a reestruturação industrial depende tanto da reestruturação espacial, quanto esta é condicionada por forças sociais que movimentam o processo industrial (LENCIONI, 1991, p.13).

Partindo dessas premissas em relação à noção de reestruturação, assim como da hipótese de que a reestruturação urbano-industrial é condicionada pelos processos de concentração e centralização na reprodução do capital e sua manifestação se configura na desconcentração da metrópole, Lencioni (1994, p.54), afirma que "se a concentração das atividades econômicas, sobretudo a concentração industrial, é que estruturou o aglomerado metropolitano, hoje é a dispersão industrial o elemento fundamental na reestruturação da metrópole de São Paulo".

No entanto, não concorda com as análises que vêm neste processo um movimento de descentralização industrial. Ao contrário, defende a ideia de que a implantação industrial fora da capital não assume o significado de uma descentralização, pois, "[...] a decisão e controle do processo de valorização do capital 
não só continuam concentrados social e espacialmente, como são reiteradamente reforçados apesar da relativa dispersão dos estabelecimentos" (LENCIONI, 1994, p.57). ${ }^{4}$

Não trabalhando com estes conceitos, mas na mesma linha de interpretação, Corrêa (1996, p.67) procura "[...] qualificar as metrópoles brasileiras enquanto centros de gestão do território, considerando para isto a intensidade, diversidade e a atuação espacial metropolitana no que se refere ao controle de atividades econômicas no espaço brasileiro".

Embora a análise de Lencioni, Corrêa e Tinoco tenham como foco a Região Metropolitana de São Paulo, ideias principais das mesmas - de que as interpretações devem ser feitas levando-se em conta a diferença tecnológica das indústrias e a distinção entre concentração e centralização espacial-, são importantes para o entendimento de outros territórios, consequentemente para o entendimento do novo mapa da indústria brasileira.

Explicitadas estas questões, outro aspecto relevante para o entendimento da nova dinâmica industrial brasileira diz respeito à produção das condições gerais de produção. Como o próprio termo indica, trata-se de condições que viabilizam um conjunto de empresas a operarem. ${ }^{5}$

Porém, a produção dessas condições não é ilimitada e por isso mesmo a dispersão territorial da indústria encontra seus limites territoriais. Assim, a idéia de desterritorialização da indústria, expressando extrema liberdade de localização do capital industrial deve ser coloca em seus devidos termos. (LENCIONI, 2003b, p.4).

Em outras palavras, as condições gerais de produção não estão distribuídas de forma uniforme, em especial aquelas mais diretamente vinculadas com as indústrias de maior intensidade tecnológica, consequentemente é uma das causas da desigual distribuição espacial da indústria pelo território nacional, assim como da dispersão diferenciada da indústria de maior intensidade tecnológica em relação àquelas mais tradicionais, de menor intensidade tecnológica.

\section{NOVO MAPA DO EMPREGO INDUSTRIAL NO BRASIL}

$\mathrm{Na}$ organização econômico-social do Brasil há um destaque considerável para a esfera da gestão, da circulação e do consumo, porém a indústria continua sendo importante na geração da riqueza social, empregando parte da população e atraindo investimentos. Compreender suas dinâmicas é fundamental para entender o arranjo espacial e seus desdobramentos no espaço geográfico.

A mesorregião geográfica em que a indústria está inserida influencia diretamente na quantidade de empregos que esta vai gerar, considerando que as 
indústrias localizadas em mesorregiões formadas por municípios bem desenvolvidos ou com fatores locacionais atrativos - infraestrutura, incentivos fiscais e mão de obra , possuem maior pessoal ocupado e maior crescimento em relação às mesorregiões pouco desenvolvidas.

Neste contexto, é fundamental analisar a quantidade de pessoal ocupado no setor industrial para compreender se houve uma retomada do processo de desconcentração industrial e como o número de empregos está distribuído nesta nova configuração espacial.

Por meio do Mapa 01 verifica-se que no ano de 1995, nove mesorregiões apresentavam maior número de pessoas ocupadas em relação às outras, sendo elas: Vale do Itajaí (101.769); Norte Catarinense (105.841); Metropolitana de Curitiba (121.128); Macro Metropolitana Paulista (154.300); Campinas (213.849); Metropolitana de Belo Horizonte (217.507); Metropolitana de Porto Alegre (265.171); Metropolitana do Rio de Janeiro (310.569) e Metropolitana de São Paulo (1.216.912).

Mapa 01: Pessoal ocupado nas indústrias das mesorregiões brasileiras em 1995

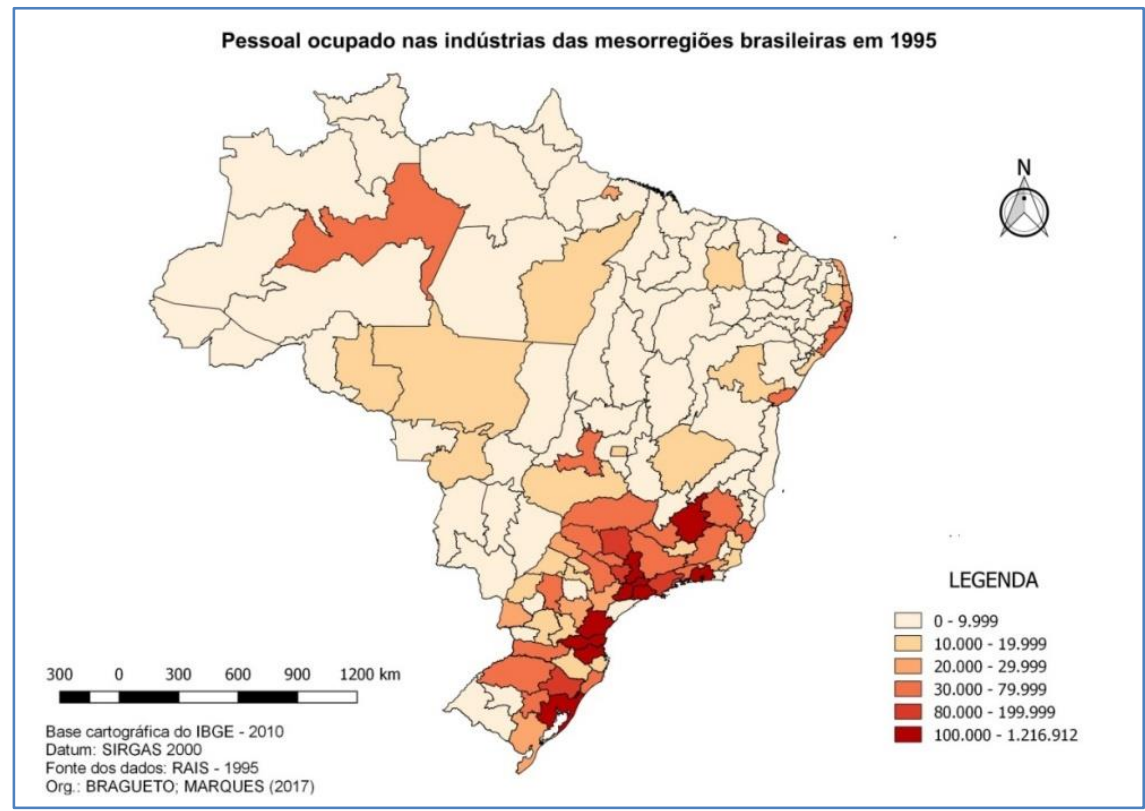

Org.: BRAGUETO; MARQUES (2017).

Em relação ao ano de 2015, representado no Mapa 02, 23 mesorregiões possuíam o maior número de trabalhadores, são elas: Triângulo Mineiro e Alto Paranaíba (101.384); São José do Rio Preto (101.611); Metropolitana de Salvador (108.470); Centro Amazonense (108.740); Metropolitana de Recife (113. 042); Vale do Paraíba Paulista (123.506); Oeste Catarinense (126.554); Sul/Sudoeste de Minas (138. 054); Centro Goiano (148. 056); Piracicaba (150. 016); Norte Central 
Paranaense (151.660); Nordeste Rio-Grandense (155.354); Metropolitana de Fortaleza (160.345); Norte Catarinense (164.521); Ribeirão Preto (167.541); Vale do Itajaí (202.123); Metropolitana de Curitiba (207.895); Macro Metropolitana Paulista (249.39); Metropolitana de Belo Horizonte (300.698); Metropolitana de Porto Alegre (305.104); Metropolitana do Rio de Janeiro (315.144); Campinas (328.509) e Metropolitana de São Paulo (1.038.876).

Mapa 02: Pessoal ocupado nas indústrias das mesorregiões brasileiras em 2015

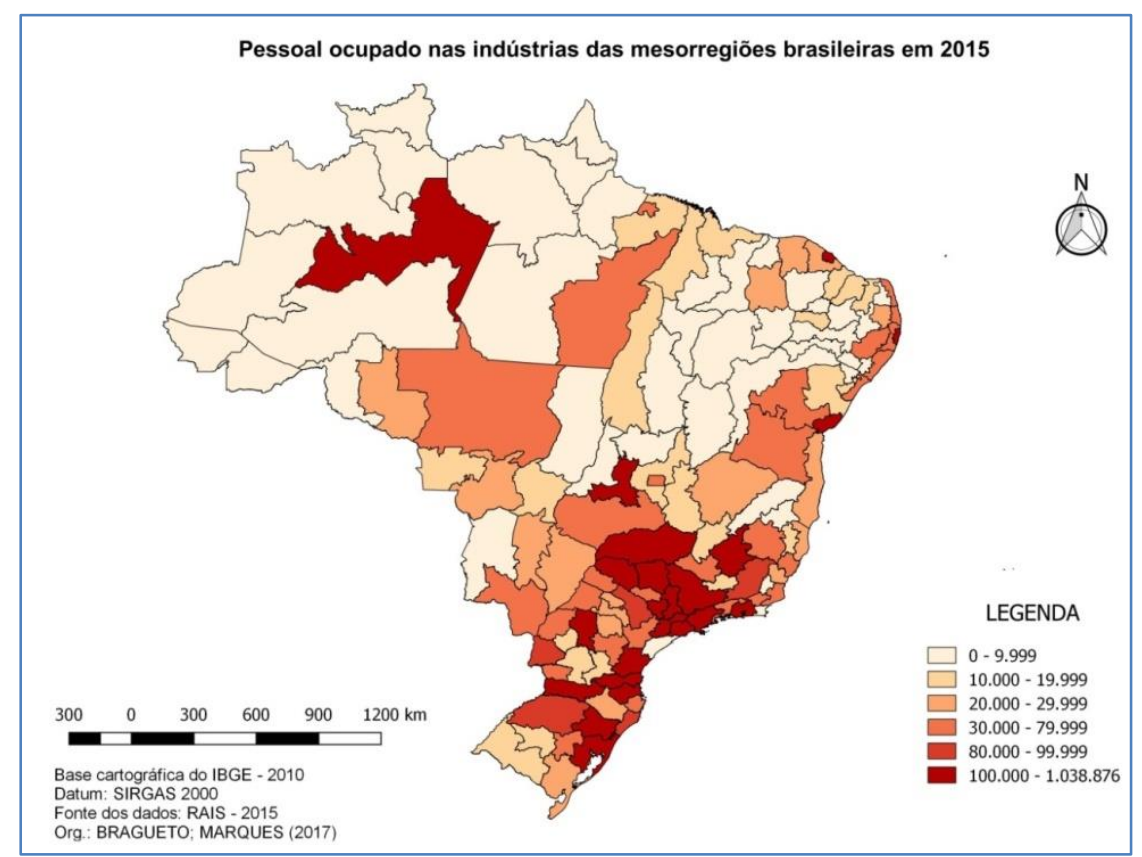

Org.: BRAGUETO; MARQUES (2017).

Comparando os Mapas 01 e 02, verifica-se que as mesorregiões com maior número de pessoas ocupadas aumentaram de nove em 1995 para 23 em 2015. Além disso, nota-se que as mesorregiões com mais de 10 mil pessoas ocupadas na indústria aumentaram expressivamente entre os anos de 1995 e 2015, sendo que em 1995 havia 66 mesorregiões e em 2015 esse número subiu para 97.

Estes dados revelam certa dispersão da indústria pelo território brasileiro, porém, se nos aprofundarmos na análise dos mesmos, observamos que ainda continua havendo um processo de desconcentração concentrada no país. Fato que pode ser comprovado, por exemplo, pelo número de pessoas ocupadas na Mesorregião Metropolitana de São Paulo, que em 1995 possuía 1.216.912 trabalhadores e em 2015 esse número decaiu para 1.038.876.

Por meio de análises no Mapa 03, constate-se que as mesorregiões que apresentaram maior crescimento entre 1995 e 2015 são: Campinas (114.660); Vale do Itajaí (100.354); Centro Goiano (99.221); Macro Metropolitana Paulista (95.090); 
Metropolitana de Curitiba (86.767); Metropolitana de Belo Horizonte (83.191); Norte Central Paranaense (82.078) e Ribeirão Preto (79.132). Estes dados apontam que o crescimento de pessoas ocupadas na indústria concentrou-se principalmente na região Sudeste do país, porém a região Sul também teve participação importante. No que se refere às mesorregiões que apresentaram decréscimo do pessoal ocupado na indústria, verifica-se que tal fato ocorreu em apenas três: Marajó (-1.926); Mata Pernambucana (-6.368) e, principalmente a região Metropolitana de São Paulo (178.036).

Mapa 03: Crescimento absoluto do pessoal ocupado nas indústrias das mesorregiões brasileiras de 1995 a 2015

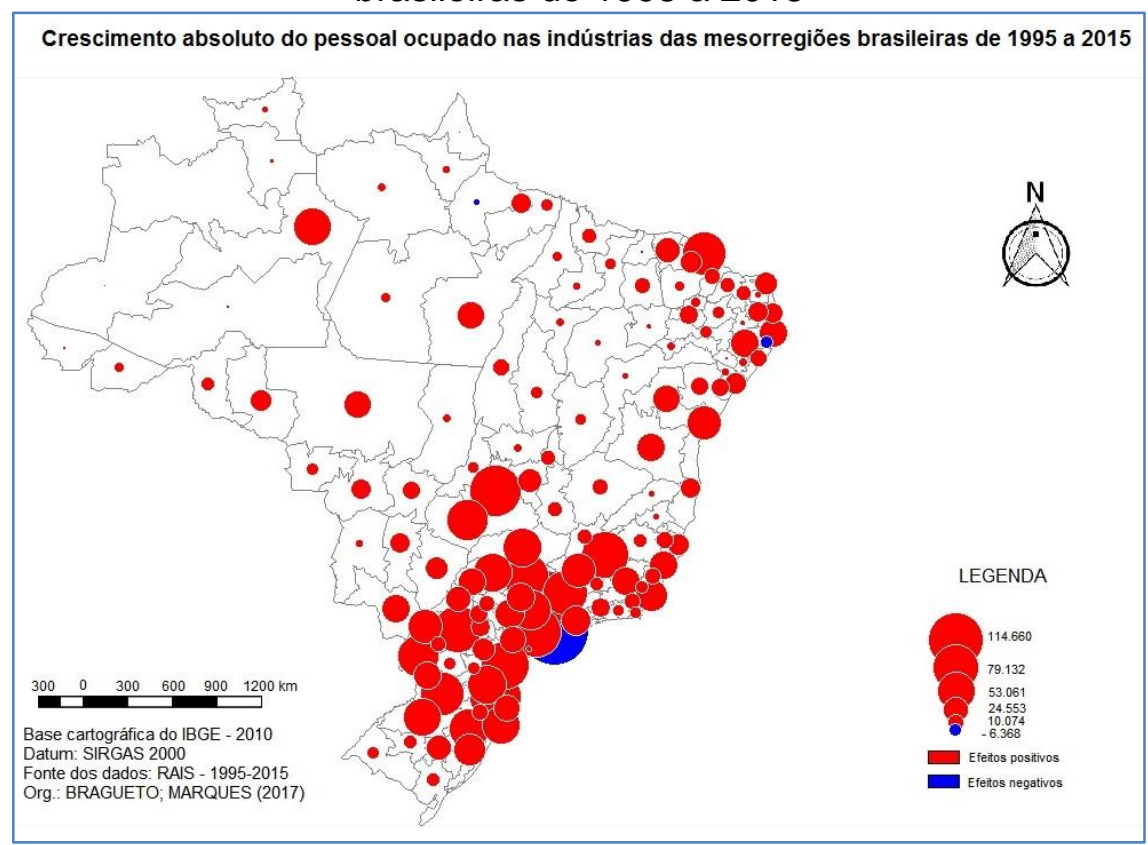

Org.: BRAGUETO; MARQUES (2017).

Se utilizarmos como parâmetro as mesorregiões que apresentaram crescimento acima de 30 mil pessoas ocupadas no setor industrial nos últimos 20 anos, verificamos que quase $70 \%$ do crescimento concentrou-se em apenas 32 mesorregiões de um total de 137 em todo o país.

Destas 32 mesorregiões, há um amplo predomínio daquelas localizadas nas regiões Sudeste, somando 13 e Sul, com 11 mesorregiões. Há ainda as mesorregiões do Nordeste que totalizam quatro, sendo que três delas são metropolitanas. Na região Centro-Oeste se destacam três mesorregiões e no Norte, há apenas uma mesorregião em crescimento significativo.

As indústrias e condições gerais de produção não estão distribuídas igualmente pelo território brasileiro e os dados mostrados acima confirmam este fato. Os maiores 
investimentos e maior crescimento concentram-se no Centro-Sul do país, contribuindo para a manutenção da desigual distribuição espacial da indústria pelo Brasil.

Há ainda os espaços geográficos desiguais dentro das próprias regiões, como no Sul, Sudeste e Centro-Oeste que apresentam maior crescimento e concentração de indústrias. A região Sudeste, por exemplo, onde se localiza a mesorregião que mais emprega, Metropolitana de São Paulo - apesar do decréscimo em seu pessoal ocupado -, existem mesorregiões com baixos índices de pessoal ocupado devido a falta de infraestrutura adequada e mão de obra especializada, como o Litoral Sul Paulista, com 4.646 trabalhadores na indústria. São mesorregiões que além de se situarem na mesma região, também estão no mesmo estado, porém com grandes desigualdades.

Portanto, constata-se que nos anos posteriores a 1994, houve um período de desconcentração do pessoal ocupada na indústria, porém trata-se de uma desconcentração concentrada, em que as mesorregiões que apresentaram maior crescimento estão, em sua grande maioria, localizadas no Centro-Sul do Brasil.

\section{CONSIDERAÇÕES FINAIS}

A indústria mostra-se fundamental na geração de riqueza social para o país e suas dinâmicas produzem espaços, excluem territórios e modificam as configurações espaciais já existentes. As atividades da indústria alteram o arranjo espacial dos lugares, sendo necessário estar atento a sua atuação para compreender o contexto das regiões do país.

A industrialização brasileira, no que se refere à concentração ou desconcentração espacial nos anos posteriores a 1970, possui dois períodos: o primeiro, entre 1970 e 1985, em que houve o auge do processo de desconcentração industrial e o segundo, de 1985 até por volta de 1994, em que houve uma inflexão do processo. Posterior a 1994, porém, alguns autores acreditam que se configuraria um terceiro período, em que houve uma retomada da desconcentração industrial.

A principal conclusão desta pesquisa é que nos anos posteriores a 1994 houve um processo de desconcentração do emprego industrial no Brasil, porém uma desconcentração concentrada, com maior crescimento das indústrias localizadas no Centro-Sul do país.

Por meio dos mapas elaborados, verifica-se as mudanças espaciais que ocorreram no país entre os anos de 1995 e 2015, com um aumento do pessoal ocupado na indústria em grande parte das mesorregiões, além do aumento expressivo 
das mesorregiões com mais de 10 mil pessoas ocupadas, o número cresceu em 31 mesorregiões.

Ao concluir que as mesorregiões mais relevantes na indústria concentram-se majoritariamente no Centro-Sul do país, constate-se a desigualdade da distribuição espacial da indústria no Brasil e que os maiores investimentos e consequentemente maior crescimento destas indústrias contribuem para a manutenção dessa desigualdade.

Ao fim desta pesquisa, nota-se como a indústria é importante para o desenvolvimento econômico e social do país ao proporcionar o crescimento da economia, melhorar o padrão de vida das pessoas, desenvolver tecnologias e gerar empregos. Utilizando como parâmetro o número de pessoal ocupado nas indústrias das mesorregiões brasileiras no ano de 2015, constata-se que a indústria gerava 7.807.388 empregos no Brasil, contribuindo diretamente para o crescimento do mesmo.

Como último aspecto a ser destacado, salienta-se que a indústria tem como característica a concentração espacial. Nesse sentido, nas próximas etapas da pesquisa se avançará nos recortes espaciais, verificando-se em cada uma das Mesorregiões relevantes, do ponto de vista do emprego industrial, quais os municípios que efetivamente apresentam um parque industrial importante.

\section{REFERÊNCIAS}

AZZONI, C.R. Indústria e reversão da polarização no Brasil. 1985. 232f. Tese (Livre-Docência em Economia) - USP-Departamento de Economia e Administração, São Paulo.

BOTELHO, Adriano. A produção do espaço e a indústria. In: Do fordismo à produção flexível. São Paulo: Annablume, 2008. p.19-30.

BRAGUETO, C.R. O Aglomerado Urbano-Industrial de Londrina: sua constituição e dinâmica industrial. 2007. 265f. Tese (Doutorado em Geografia Humana) - Faculdade de Filosofia, Letras e Ciências Humanas, Universidade de São Paulo, São Paulo.

CANO, W. Concentração e desconcentração econômica regional no Brasil: 1970/95. Economia e Sociedade, Campinas, n.8, p.101-141, jun. 1997.

CORRÊA, Roberto Lobato. Metrópoles, corporações e espaço: uma introdução ao caso brasileiro. In: CASTRO, I.E.de; GOMES, P.C.da C.; CORRÊA, R.L. (org.) Brasil: questões atuais da reorganização do território. Rio de Janeiro: Bertrand Brasil, 1996. p.67-114

DINIZ, Clélio Campolina. A dinâmica regional recente da economia brasileira e suas perspectivas. Brasília: IPEA, 1995. (Texto para Discussão no 375)

DINIZ, Clélio Campolina; CROCO, Marco Aurélio. Reestruturação econômica e impacto regional: o novo mapa da indústria brasileira. Nova Economia, Belo Horizonte, v.6, n.1, p.77-103, 1996. 
FIRKOWSKI, Olga Lúcia C. A nova territorialidade da indústria e o aglomerado metropolitano de Curitiba. 2001. 278f. Tese (Doutorado em Geografia Humana) Faculdade de Filosofia, Letras e Ciências Humanas, Universidade de São Paulo, São Paulo.

LENCIONI, Sandra. Cisão territorial da indústria e integração regional no Estado de São Paulo. In: GONÇALVES, M.F.; BRANDÃO, C.A.; GALVÃO, A.C.F. (org.).

Regiões e cidade, cidades nas regiões: o desafio urbano-regional. São Paulo: Ed. UNESP; ANPUR, 2003a. p.465-476

Condições gerais de produção: um conceito a ser recuperado para a compreensão das desigualdades de desenvolvimento regional. Scripta Nova. Revista electrónica de geografía y ciencias sociales. Barcelona: Universidad de Barcelona, 1 de agosto de 2007, vol. XI, núm. 245 (07). Disponível em: <http://www.ub.es/geocrit/sn/sn-24507.htm>.

A emergência de um novo fato urbano de caráter metropolitano em São Paulo. A particularidade de seu conteúdo sócio-espacial, seus limites regionais e sua interpretação teórica. In: ENCONTRO NACIONAL DA ANPUR, 10, 26 a 30 de maio, 2003, Belo Horizonte. Anais... Belo Horizonte: ANPUR, 2003b.

. Reestruturação urbano-industrial: centralização do capital e desconcentração da Metrópole de São Paulo. 1991. Tese (Doutorado em Geografia Humana)) - Faculdade de Filosofia, Letras e Ciências Humanas, Universidade de São Paulo, São Paulo.

Reestruturação urbano-industrial no Estado de São Paulo: a Região da Metrópole Desconcentrada. Espaço \& Debates, n.38, p.54-61, 1994.

SPOSITO, Maria Encarnação Beltrão. Concentração e centralização. In:

O chão em pedaços: urbanização, economia e cidades no estado de São Paulo. 2004. Tese (Concurso de Livre Docência) - UNESP, Presidente Prudente. f.217-224

TINOCO, A. de C. Integração ou fragmentação? O impasse gerado pelo fetichismo da desconcentração. Espaço \& Debates, n.41, p.46-65, 2001.

\footnotetext{
1 Claudio Roberto Bragueto. Professor Adjunto na Universidade Estadual de Londrina Departamento de Geociências. Cx. Postal 10.011 - CEP 86.057-970 - Londrina - PR. bragueto@uel.br

${ }^{2}$ Ana Carolina dos Santos Marques. Graduanda em Geografia na Universidade Estadual de Londrina - Departamento de Geociências. Cx. Postal 10.011 - CEP 86.057-970 - Londrina PR. anaaa0@hotmail.com

${ }^{3}$ Tinoco (2001, p.46) se refere a três períodos: a) primeiro período (até 1970): intensa concentração; b) segundo período (1970-1985): auge do processo de desconcentração; c) terceiro período (1985-1995): período de impasse.

4 Para maiores detalhes sobre a discussão dos conceitos de desconcentração e descentralização ver Lencioni (1994, p.57 e seguintes), Spósito (2004) e Lencioni (2003a).

${ }^{5}$ Para aprofundamento sobre o conceito ver Lencioni (2007).
} 